\title{
FUNCTIONAL CALCULUS WITH OPERATOR-MONOTONE FUNCTIONS
}

\author{
TSUYOSHI ANDO
}

Abstract. Let $f(t)$ be a non-negative operator-monotone function defined on $[0, \infty)$, and $A, B$ positive definite operators on a Hilbert space. The inequalities $\langle B x, x\rangle \leqslant f(\langle A x, x\rangle)$ for every unit vector $x$ do not imply the operator inequality $B \leqslant f(A)$. We prove, however, that when combined with the inequalities $\left\langle B^{-1} x, x\right\rangle^{-1} \geqslant f\left(\left\langle A^{-1} x, x\right\rangle^{-1}\right)$, the relation $B=f(A)$ follows.

Mathematics subject classification (2010): 47A60, 47A63.

Keywords and phrases: Operator-monotone function, functional calculus, operator inequality, positive definite operator.

\section{REFERENCES}

[1] T. Ando, Comparison of norms ||$|f(A)-f(B)|||$ and ||$|f(|A-B|)|||$, Math. Z. 177 (1988), 403-409.

[2] R. Bhatia, Matrix Analysis, Springer, Berlin-Heidelberg-New York, 1996.

[3] R. Bhatia AND T. SANo, Loewner matrices and operator convexity, 2008, Math. Ann., (to appear).

[4] F. HANSEN AND G.K. PEDERSEN, Jensen's inequality for operators and Löwner's theorem, Math. Ann. 258 (1982), 229-241.

[5] T. Hayashi, Non-commutative A-G mean inequality, Proc. Amer. Math. Soc., (to appear).

[6] M. UchiYAma, A new majorization between functions, polynomials, and operator inequalities, J. Funct. Anal. 231 (2006), 231-244. 